\title{
ROUSSEAU E A EDUCAÇÃO DA INFÂNCIA
}

\author{
ROUSSEAU AND CHILDHOOD EDUCATION
}

Rosiris Pereira de Souza*

\begin{abstract}
Resumo: O objetivo principal deste artigo é compreender o pensamento político, filosófico e pedagógico de Jean-Jaques Rousseau e, a partir disso, situar sua contribuição para a constituição do pensamento pedagógico brasileiro e, principalmente, para se pensar as propostas educativas para a infância. Para a construção deste texto, fizemos leituras e estudos a partir das obras: Discurso sobre as origens e fundamentos das desigualdades entre os homens (1999), Do Contrato Social (2000) e Emílio ou da Educação (2004), buscando identificar os princípios e máximas fundamentais desse filósofo do século XVIII e objetivando refletir sobre relação entre sua concepção de sociedade e a formação dos indivíduos dentro da corrente naturalista-idealista.
\end{abstract}

Palavras-chave: Educação da Infância; Sociedade; Jean-Jacques Rousseau.

Summary: The main purpose of this article is to understand the political, philosophical and pedagogical thoughts of Jean Jacques Rousseau and based on that comprehension place its contribution to the constitution of the Brazilian pedagogical thinking and, most important, to think his proposals to childhood's education. For the construction os this text, readings and studies were done from the works: Speech about the origins and foundations of inequalty amog men (1999); The social Contract (2000) and Emílio or From the education (2004) seeking to identify this autor's principles and maxims during the XVIII century aiming a reflection about the conexion between his conception of society and the training of individuals within the naturalistic current - idealistic.

Keywords: Children's education; Society; Jean-Jacques Rousseau

\section{INTRODUÇÃO}

O objetivo principal do texto é refletir sobre o pensamento político, filosófico e pedagógico de Jean-Jaques Rousseau e, a partir disso, compreender sua contribuição para a constituição do pensamento pedagógico brasileiro, principalmente para entender a origem de onde partem muitas propostas pedagógicas para a educação infantil. Para a construção deste

\footnotetext{
* Doutoranda do Programa de Pós-Graduação em Educação da Universidade de Brasília. Atualmente é professora e pesquisadora em regime de Dedicação Exclusiva na Universidade Federal de Goiás. E-mail: rosirisps@gmail.com.
} 
artigo, fizemos leituras e estudos das obras: Discurso sobre as origens e fundamentos das desigualdades entre os homens (1999), Do Contrato Social (2000) e Emílio ou da Educação (2004), buscando identificar os princípios e máximas fundamentais desse filósofo do século XVIII, o que nos motivou a fazer um exercício reflexivo sobre relação entre sua concepção de sociedade e a formação dos indivíduos. Temos clareza de que não é sensato tomar uma obra ignorando o tempo em que ela é datada, ou seja, sem levar em consideração seu contexto histórico. Também não ignoramos as controvérsias e críticas a esse filósofo e sua obra, considerado por muitos como espontaneísta e pai da Escola Nova, também reconhecido como um dos principais representantes do naturalismo a partir da corrente de pensamento idealista. O fundamental neste ensaio é compreender o sistema filosófico do autor para entender as respostas encontradas por ele, que desnudam a sociedade de sua época, e assim compreender seu tratado sobre a educação.

Nesse sentido, organizamos o presente texto em dois momentos: o primeiro, tem como finalidade traçar algumas inter-relações entre as obras Discurso sobre a origem e os fundamentos da desigualdade entre os homens (1999), Do Contrato Social (2000) e Emílio ou da Educação (2004), com o olhar voltado para a compreensão dos princípios fundamentais de Rousseau sobre a sociedade e a formação do indivíduo, em especial, a forma como esse filósofo pensa a criança e sua educação; o segundo momento busca aprofundar as análises das questões centrais tecidas no tratado filosófico sobre a educação presente na obra Emílio.

Para refletir sobre a relação entre sociedade e a formação dos indivíduos a partir do pensamento de Rousseauniano, achamos importante levar em consideração as ponderações feitas por Guimarães em sua tese de doutoramento com o tema: "A Recusa da sociedade do espetáculo no processo de formação do homem autônomo" (2004), na qual Rousseau é considerado um mirante,

E, como todo bom mirante, situa-se no alto. Portanto, é necessário escalar a montanha e, nesse percurso, apontar os percalços, as dificuldades inerentes àquele que escala, isto é, aprender com ele. [...] mas olha-se basicamente para as circunstâncias de Rousseau para examinar as respostas dadas por ele a tais circunstâncias (GUIMARÃES, 2004, p.15).

Adicionamos mais uma observação às aqui apresentadas por Guimarães, para não atentarmos somente para as soluções e novas questões encontradas por aquele que se situa no alto, e sim, nas possibilidades analíticas sobre um determinado objeto ou fenômeno que seu sistema filosófico nos oferece. 
Rousseau nos apresenta uma perspectiva para enxergar a realidade, não como ela se apresenta, mas, segundo ele, como realmente é. O teórico compreende a realidade sob a "perspectiva da natureza" ou "estado perfeito". Essa máxima traduz o pensamento de Rousseau em Do Contrato Social, no qual afirma que é a partir do ideal que devemos olhar o real, e que isso nos possibilitaria projetar além, para o que a sociedade deveria ser. No campo social, ele tem como ideal o estado de natureza e, a partir desse estado, ele faz a leitura da realidade, que é o estado civil e desse ponto projeta o seu Contrato Social (república). Para entender essa perspectiva e a unidade de pensamento do autor, vamos visitar alguns aspectos de sua vida e obras no contexto do século XVIII.

\section{Jean-Jacques Rousseau, a sociedade e a formação do indivíduo}

Jean-Jacques Rousseau nasceu em 1712 e é considerado um dos maiores pensadores do século XVIII. Sua produção intelectual inspirou várias reformas educacionais. Escreveu sua obra filosófica de várias formas, entre elas: tratados, romances, cartas e também sua autobiografia. Suas principais obras são: Discurso sobre a origem das desigualdades entre os homens, Ensaio sobre a origem das línguas, Discurso sobre as Ciências e as Artes, As confissões de Jean-Jacques Rousseau, Os devaneios do caminhante solitário, Do Contrato Social e Emílio ou Da Educação.

Na cronologia elaborada por Milton Meira do Nascimento ${ }^{1}$, citada por Cerizara (1990) podemos acompanhar a produção intelectual e alguns aspectos da vida desse filósofo que influenciou por vários séculos distintas correntes pedagógicas.

Do nascimento até 1730 , podemos destacar sua fuga de Genebra, sua conversão ao catolicismo, seu emprego como criado na casa do Sr. Gouvon e também como professor de música. Em 1740, torna-se preceptor e três anos depois escreve sua primeira obra, intitulada Dissertação sobre a música moderna. No ano seguinte termina a redação de As musas galantes e, em 1749, redige o Discurso sobre as ciências e as artes, pelo qual é premiado na Academia de Dijon. Em 1753, escreve a Carta sobre a música francesa e, neste mesmo ano, é ameaçado de prisão por suas ideias. Nesse período retorna ao protestantismo e recupera seus direitos como cidadão. Em 1755, publica Discurso sobre a origem e os fundamentos da desigualdade entre os homens, uma de suas principais obras, e logo no ano seguinte escreve a

\footnotetext{
${ }^{1}$ Milton Meira do Nascimento é professor de Ética e Filosofia Política da Faculdade de Filosofia da USP escreveu o prefácio e a cronologia de J. J. Rousseau no Livro de Ana Beatriz Cerizara (1990).
} 
Carta sobre a previdência, sendo que, ao mesmo tempo, iniciava a redação de $A$ nova Heloísa. Em 1758, redige a primeira versão da Profissão de fé do vigário de Savoia e, um ano depois, elabora a primeira versão do Emílio. No ano seguinte, faz mais duas versões de Emílio e trabalha simultaneamente na redação de Do Contrato Social, (obras que fundamentam este artigo). No ano de 1762, publica Emílio e Do contrato Social, em Genebra. Em Paris, as duas obras são condenadas, fato que força Rousseau a se refugiar em Motiers. Em 1763 redige o Projeto de Constituição para a Córsega e, em 1764, inicia a redação das Confissões. No ano de 1766, vai para Londres e, em 1771, elabora as Considerações sobre o Governo da Polônia e, logo em seguida (dois anos depois), redige os Diálogos: Rousseau, juiz de Jean-Jacques. Em 1776 termina os Diálogos e inicia os Devaneios do caminhante solitário deixando-o inacabado.

Entre suas obras, destacamos a publicação de Emílio ou Da Educação e Do Contrato Social que datam de 1762, como obras importantíssimas para a compreensão do pensamento desse filósofo. A primeira aborda um tratado sobre educação, e a segunda é considerada o mais importante trabalho sobre filosofia política. A condenação dessas obras pelo parlamento de Paris no mesmo ano da publicação foi motivada por conterem ideias contrárias ao governo e também à religião.

É importante destacar que Rousseau é apontado com o responsável pelo pioneirismo, ainda no século XVIII, pela forma diferenciada de se olhar para a infância e sua educação. Concebeu a infância como uma fase essencial na constituição do ser humano e na sua relação com a sociedade. Afirmava que, na sociedade de sua época (Europa, século XVIII), havia um valor negativo da infância, pois deplorava-se esse período do desenvolvimento humano. Contrário a essa ideia, Rousseau defendia que a sociedade não conseguia perceber que a raça humana teria perecido se o homem não tivesse começado sendo criança. Para ele, o período da infância é essencial para o ato educativo.

Nascemos fracos, precisamos de força, nascemos carentes de tudo, precisamos de assistência, nascemos estúpidos, precisamos de juízo. Tudo o que não temos ao nascer e de que precisamos quando grandes nos é dado pela educação (ROUSSEAU, 2004, p. 09).

Rousseau reconhece a importância da condição infantil quando nos mostra que é pela educação da criança que se molda o homem, quando afirma que se o homem já nascesse 
grande e forte, essas duas qualidades não lhe serviriam para nada até que tivesse aprendido como usá-las.

Para compreensão de alguns princípios e máximas que estão presentes em Emílio e Do Contrato Social retomaremos também outra obra de suma importância para a leitura de Rousseau e entendimento de seu sistema filosófico que é o Discurso sobre as origens e os fundamentos da desigualdade entre os homens. Neste escrito filosófico, Rousseau nos adverte da difícil missão, e ao mesmo tempo a mais interessante para a filosofia, que é conhecer a origem da desigualdade entre os homens.

Pois como conhecer a fonte das desigualdades entre os homens se não se começar por conhecer a eles mesmos? E como o homem conseguiria ver-se tal como o formou a natureza através de todas as mudanças provocadas em sua constituição original pela sucessão dos tempos e das coisas e distinguir o que pertence à sua própria natureza daquilo que as circunstâncias e seus progressos acrescentaram ao seu estado primitivo ou nele mudaram? (ROUSSEAU, 1999, p. 149).

Para Rousseau, é a partir da compreensão da sociedade e suas instituições que se pode pensar o processo de formação do indivíduo, e essa é a ideia desenvolvida em Emílio. A educação do indivíduo objetiva prepará-lo para viver em sociedade: esse indivíduo seria autônomo e livre e suportaria as circunstâncias (vícios) da realidade social.

No Contrato Social (1999), podemos perceber a base da construção do pensamento de Rousseau e nesta argumentação destacamos a forma como ele relaciona os três estados: o estado de natureza, o estado civil e o contrato social. O primeiro e o último estados são hipotéticos, ideais. Retomamos aqui a ideia de um estado ideal servindo como parâmetro para se descortinar o que é o estado civil e também para desenvolver como deveria ser o contrato social.

Podemos entender os três estados representando da seguinte forma: o primeiro é o estado de natureza (hipotético), o segundo é o estado civil (real) e o terceiro é o estado do contrato social (também hipotético). Podemos ainda identificar dentro do primeiro estado dois momentos: um compreendido como Estado de natureza chamado de Marco zero, que mostra o homem primitivo sem os benefícios da associação (coletivo) e o segundo momento que é identificado por Rousseau como o Estado em que o homem foi mais feliz, pois possuía os benefícios da associação sem, no entanto, ter perdido ainda os benefícios do Estado de natureza. Segundo Rousseau, não foi possível ao homem manter-se, nesse momento, por uma 
característica inerente ao ser humano: a perfectibilidade, que é a necessidade do homem de transformar-se sempre.

Antes do encadeamento de prodígios, momento em que o homem conhecia tão somente as desigualdades naturais como idade, saúde, altura, força, qualidades do espírito, o homem vivia, segundo Rousseau, no estado de natureza. Após, por força de uma espécie de convenção, foram acrescentadas às diferenças naturais os privilégios de que gozam alguns em detrimentos de outros. Essa condição, ao contrário daquela, foi forjada pelo interesse calculado em benefício individual, definida como estado de sociedade, ou estado civil (ROUSSEAU, 1999, p. 47).

O homem no estado civil não seria "nada" demonstrando com essa expressão um processo de degradação ou degeneração da humanidade, o homem sendo constituído somente de aparência, nada mais que uma imagem construída a partir da visão do outro. Ao mesmo tempo, o autor tenta advogar que o homem não nasce assim, são as circunstâncias adversas da sociedade civil que o degeneram.

$\mathrm{Na}$ formação desse homem seria então importante agir sobre as circunstâncias que o rodeiam. Se considerarmos a sociedade como produto da ação do homem, essa situação também nos coloca diante da possibilidade da capacidade de o homem produzir outro modelo de sociedade. Para Rousseau, essa construção somente seria possível se fosse realizada pelo homem livre e autônomo e esses seriam os princípios fundamentais a serem observados na educação desse homem.

Em relação à sociedade, em Do Contrato Social, Rousseau busca responder a uma questão primeira que é a tese sobre a qual se debruça na tentativa de encontrar uma forma de associação (Contrato Social) para resolver um problema fundamental:

Achar uma forma de sociedade que defenda e proteja com toda a força comum, a pessoa e os bens de cada sócio, e pela qual unindo-se cada um a todos, não obedeça, todavia, senão a si mesmo e fique tão livre como antes (ROUSSEAU, 2000, p. 29)

No desenvolver de suas reflexões, Rousseau apresenta a forma que, para ele, seria a ideal: o contrato social. Nele os homens se associariam e não seriam submissos, alienando a vontade particular de cada um à vontade geral, beneficiando a todos. Porém, a vontade geral, para Rousseau, é sempre esclarecida.

Nesse contrato está presente a ideia de um corpo social em que os indivíduos, em nome do bem comum, abririam mão de sua liberdade individual em prol da liberdade social, 
estando assim preservada sua liberdade natural. Essa forma de alienação ${ }^{2}$ é muito importante e esclarecedora para se entender o pensamento de Rousseau.

Percebemos aqui uma concepção de sociedade que diverge da realidade em que viveu Rousseau, um estado hipotético de sociedade que se aproxima da ideia também colocada para a formação de Emílio, aluno imaginário, que Rousseau pretende educar com ideias e princípios pedagógicos baseados no naturalismo. Essas ideias também transcendem ao modelo de educação de sua época.

É importante perceber ainda no Contrato Social, que, para Rousseau, importa a formação do cidadão e, em Emílio, a prioridade é a formação do indivíduo, o que, de certa forma e contraditoriamente, aproxima as duas obras, quando percebemos que o filósofo permanece fiel à sua forma de perceber e analisar a sociedade e o homem.

O homem nasceu livre, e por toda a parte geme agrilhoado: o que julga ser senhor dos demais é de todos o maior escravo. Donde veio tal mudança? Ignoro. Que o legitima? Esta questão creio poder responder" (ROUSSEAU, 2000, p. 21).

Nesta passagem encontra-se o homem em sociedade, que, para Rousseau, não passa de um escravo, mesmo aquele que está em uma situação de poder, e que não difere de todos os outros na condição de escravidão. Ao traçar hipoteticamente a educação de Emílio, Rousseau vê justamente a possibilidade de um tratado pedagógico que formaria o indivíduo para a autonomia e a liberdade e não para a submissão aos vícios sociais.

Rousseau tem como objetivo no seu tratado de educação pensar a formação do homem livre, capaz de autonomamente se defender de todos os problemas (vícios) da sociedade civil. $\mathrm{E}$, da mesma forma, pensava uma sociedade diferente daquela que criticava. Para nosso entendimento essa é a linha condutora do pensamento de Rousseau para pensar a educação e a sociedade.

\section{Emílio: um tratado filosófico sobre educação}

Na obra Emílio ou Da Educação, Rousseau vislumbra hipoteticamente a possibilidade da Educação do indivíduo. Como exposto anteriormente, é fundamental situar autor e obra no tempo, pois, estamos falando da segunda metade do século XVIII, na qual a sociedade vive as questões da classe burguesa na Europa e, nesse contexto, Rousseau inaugura uma nova forma de entender a infância.

\footnotetext{
${ }^{2}$ Alienar significa aqui cessão de bens.
} 
De acordo com Cerizara (1990), contraditoriamente ao pensamento filosófico da época, Rousseau se destacava por sua forma de pensar e por sua escrita pautada, principalmente em Emílio, nos fatos cotidianos, para demonstrar sua teoria filosófica. Outra característica marcante é o fato de sua escrita estar em primeira pessoa, destoando da escrita da época e demonstrando ainda uma maneira peculiar de pensar as questões que afetavam a humanidade.

Rousseau tenta explicar filosoficamente como fazer para que seu aluno se torne livre mesmo vivendo em uma sociedade corrompida pela ação dos próprios homens. O princípio fundamental de sua análise sobre o homem pressupõe que ele seja naturalmente bom e que a sociedade é responsável por sua corrupção e degeneração.

O fato de Rousseau ter publicado Do Contrato Social e Emílio simultaneamente pode nos levar a pensar na existência de um fio condutor na construção do sistema filosófico que perpassa as duas obras, estabelecendo uma relação muito complexa ao se pensar a relação entre a formação do cidadão e a formação do indivíduo.

Podemos identificar uma unidade de pensamento quando entendemos que a proposta de Rousseau buscava refletir e compreender como as coisas são, para então apontar como poderiam ser, ou de entender o homem como é para propor como deveria ser.

As obras compõem um sistema filosófico e é necessário conhecê-las para se compreender as bases desse sistema, ou seja, fazer um exame profundo das partes nas quais se encontram a estrutura e a articulação lógica do discurso de Rousseau.

O homem, para Rousseau, em seu estado de natureza, nasce igual a qualquer animal, possui instinto e necessidades de alimentação, preservação, repouso e tenta, ao mesmo tempo, afastar o temor que se materializa em dor ou fome. Já em relação à sociedade, no estado civil convive-se com a opressão e a corrupção e nesse sentido o homem se encontra a "ferros", ou seja, aprisionado, escravo de várias circunstâncias.

No Contrato Social é fundamental que a vontade geral seja esclarecida. Essa vontade geral prioriza o bem comum e não o interesse particular de cada membro do contrato. Essa vontade esclarecida é a intenção da formação de Emílio, um homem livre e autônomo e, portanto, esclarecido.

O homem natural é tudo para si mesmo: é a unidade numérica, o inteiro absoluto, que só se relaciona consigo mesmo ou com seu semelhante. $\mathrm{O}$ homem civil é apenas uma unidade fracionária que se liga ao denominador e cujo valor está em sua relação com o todo, que é o corpo social. As boas 
instituições sociais são as que melhor sabem desnaturar o homem, retirar-lhe sua existência absoluta para dar-lhe uma relativa, e transferir o eu para a unidade comum, de sorte que cada particular já não se julgue como tal, e sim como uma parte da unidade, e só seja perceptível no todo (ROUSSEAU, 1999, p.12).

Em Emílio percebemos os princípios fundamentais e a lógica do sistema filosófico de Rousseau que também já estavam inscritos no Discurso sobre as origens e os fundamentos das desigualdades entre os homens e no Contrato Social. Fica claro que Emílio não se trata de um projeto ou de um plano pedagógico, também não se trata de uma proposta que poderia ser aplicada. Em outras palavras, poderíamos dizer que Emílio trata-se de uma obra filosófica, ou seja, um tratado filosófico sobre educação, da mesma forma que Do Contrato Social é uma obra de filosofia política e que, portanto, ambas não devem ser lidas como uma fórmula de aplicação prática imediata a uma dada realidade para resolução dos problemas da educação ou da sociedade. Estas obras têm seu valor relacionado à sua potencialidade de análise e compreensão do indivíduo e da sociedade em um tempo determinado por uma concepção idealista de mundo.

Podemos inferir que, acima de tudo, a obra Emílio pressupõe um acordo ideal entre aquele que quer aprender e nada sabe e aquele que diz que sabe e quer ensinar. Pressupõe, portanto, que tanto aluno quanto mestre se apresentam no plano ideal-hipotético. No tratado educacional de Rousseau tanto mestre quanto aluno se deslocam de seus lugares em uma relação que prioriza o saber.

Rousseau, em Emílio, estabelece um pêndulo entre o aluno real e o aluno ideal, e se coloca como mestre imperfeito, ou seja, o mestre para ele não é isento de falhas, porque também está na relação entre o homem, Rousseau, e o Mestre, em Emílio. O pensador considera a Educação como arte e enquanto tal acredita na impossibilidade de êxito total. É sempre uma aposta.

Rousseau quer discutir profundamente a educação no plano do devir, pois, concebe a sociedade corrompida e, portanto, educar nessa sociedade seria educar para a corrupção. Retira assim seu aluno do tempo histórico, "afasta os fatos" e, dessa forma e nesse plano, pensa a formação ideal (natural) para o homem ideal. O filósofo se propõe a falar do tempo lógico e não mais do tempo histórico.

No livro I de Emílio, no qual nos baseamos para pensar a infância em Rousseau, é apresentado que a Educação, em sentido amplo, possui três mestres: a) a natureza; b) os 
homens e; c) as coisas. A educação pela natureza pressupõe uma educação que não depende dos homens e está relacionada aos órgãos internos (tais como os reflexos do bebê ao nascer). A educação dos homens seria o aprender e o fazer uso de nossas faculdades. A educação das coisas nos é dada pelo ganho de nossas próprias experiências na relação com o ambiente (como exemplo, podemos citar o uso de instrumentos rudimentares por homens primitivos, que somente em alguns aspectos são controlados pelo homem).

A educação vem-nos da natureza ou dos homens ou das coisas. O desenvolvimento interno de nossas faculdades e de nossos órgãos é a educação da natureza; o uso que nos ensinam a fazer desse desenvolvimento é a educação dos homens; e a aquisição de nossa própria experiência sobre os objetos que nos afetam é a educação das coisas (ROUSSEAU, 2004, p. 09).

No tratado de Rousseau, somente na educação dos homens é que nos cabe ser senhores e, mesmo assim, por suposição, por não se poder prever e dirigir inteiramente tudo o que circunda uma criança.

Ora, dessas três educações diferentes, a da natureza não depende de nós; a das coisas, só em alguns aspectos. A dos homens é a única de que somos realmente senhores; mesmo assim, só o somos por suposição, pois quem pode esperar dirigir inteiramente as palavras e as ações de todos os que rodeiam uma criança? (ROUSSEAU, 2004, p. 09)

E qual seria o alvo dessa educação? Para Rousseau, seria o mesmo da natureza, já que o concurso da educação dos três mestres aqui apresentados aponta para a perfeição.

O conceito de natureza é determinante em Rousseau e podemos entendê-lo da seguinte forma:

Nascemos sensíveis e, desde o nascimento, somos afetados de diversas maneiras pelos objetos que nos cercam. Assim que adquirimos, por assim dizer, a consciência de nossas sensações, estamos dispostos a procurar ou evitar os objetos que as produzem, em primeiro lugar conforme elas sejam agradáveis ou desagradáveis depois, conforme a conveniência ou inconveniência que encontramos entre nós e esses objetos, e, enfim, conforme os juízos que fazemos sobre a ideia de felicidade ou de perfeição que a razão nos dá. Essas disposições estendem-se e firmam-se à medida que nos tornamos mais sensíveis e mais esclarecidos; forçadas, porém, por nossos hábitos, elas se alteram mais ou menos segundo nossas opiniões. Antes de tal alteração, elas são o que chamo em nós a natureza (ROUSSEAU, 2004, p. 10-11). 
Rousseau questiona sobre o que temos que fazer para formar homem autônomo e livre. Parte do princípio de que devemos, antes de tudo, impedir que algo seja feito (ROUSSEAU, 2004, p. 14). Conforme o seu tratado, é muito importante pensar considerando a ordem natural e, para explicitar essa asserção, selecionamos uma passagem em que isto é demarcado por nosso autor:

$\mathrm{Na}$ ordem natural, sendo os homens todos iguais, sua vocação comum é a condição de homem, e quem quer que seja bem educado para tal condição não pode preencher mal as outras relacionadas com ela. Pouco me importa que destinem meu aluno à espada, à igreja ou à barra. Antes da vocação dos pais, a natureza o chama para a vida humana. Viver é o ofício que quero ensinar-lhe. Ao sair de minhas mãos, concordo que não será nem magistrado, nem soldado, nem padre, será homem em primeiro lugar; tudo o que um homem deve ser, ele será capaz de ser, se preciso, tão bem quanto qualquer outro; e, ainda que a fortuna o faça mudar de lugar, ele sempre estará no seu (ROUSSEAU, 2004, p. 15).

No plano da sociedade civil, Rousseau critica a sabedoria apontando que todo conhecimento de seu tempo está embasado em preconceitos servis e que "todos os nossos costumes não passam de sujeição, embaraço e constrangimento. O homem civil nasce, vive e morre na escravidão; enquanto conservar a figura humana, estará acorrentado por nossas instituições” (ROUSSEAU, 2004, p. 16). Aponta que na educação da criança pequena há uma pretensão de moldá-la desde o seu nascimento.

Rousseau critica a falta de liberdade de movimentos na infância. Contrário a essa ideia, ele defende que a criança recém-nascida precisa de muitos movimentos,

Pretende-se que as crianças em liberdade poderiam adotar más posições e fazer movimentos capazes de atrapalhar a boa conformação dos membros. Este é um dos vãos raciocínios de nossa falsa sabedoria, jamais confirmados por nenhuma experiência. Da multidão de crianças que, entre povos mais sensatos do que nosso, são criadas com toda a liberdade de seus membros, não se vê uma só que se fira ou se mutile; não dariam a seus movimentos a força que pudesse torná-los perigosos e, quando assume uma posição violenta, a dor logo as adverte de que devem mudá-la (ROUSSEAU, 2004, p.19).

As reflexões de Rousseau sobre a formação do indivíduo permitem depreender o que se ensina para as crianças e o que se deveria ensinar. Fica muito clara essa ideia na passagem sobre o domínio e a servidão, destacando-se que, antes mesmo de falar, as crianças passam por experiências que as colocam diante desses princípios “(...) antes de falar ela dá ordens, 
antes de poder agir ela obedece, às vezes, castigam-na antes que possa conhecer seus erros, ou melhor, cometê-los" (ROUSSEAU, 2004, p. 25).

As máximas pedagógicas de Rousseau passam por princípios que objetivam, na formação do indivíduo, mantê-lo o maior tempo possível no caminho da natureza. Explicita suas máximas da seguinte forma:

É preciso ajudá-las a suprir o que lhes falta, quer em inteligência, quer em força, em tudo o que diz respeito à necessidade física. [...] no auxílio que lhes prestamos, devemos limitar-nos unicamente ao realmente útil, sem nada conceber a fantasia ou ao desejo irrazoável, pois a fantasia não as atormentará enquanto não se a fizer nascer, dado que ela não pertence à natureza. [...] é preciso estudar com atenção sua linguagem e seus sinais, para que, numa idade em que elas não sabem fingir, distingamos em seus desejos o que vem da opinião. [...] O espírito destas regras é dar às crianças a mais verdadeira liberdade e menos domínio, deixar que façam mais por si mesmas e exijam menos dos outros. Assim, acostumando cedo a limitar os seus desejos às suas forças, pouco sentirá a privação do que não estiver em seu poder (ROUSSEAU, 2004, p. 58).

Segundo Rousseau, o espírito dessas máximas visa dar às crianças mais liberdade (verdadeira) e menos domínio (forças), buscando equilibrar os desejos e as forças de realizálos. Em relação à linguagem, Rousseau afirma que "a criança que quer falar só deve escutar as palavras que pode entender" e acrescenta ainda que:

O maior mal da precipitação com que se faz as crianças falarem antes da hora não é o fato de as primeiras palavras que lhes dirigimos e as primeiras que elas falam não terem nenhum sentido para elas, mas sim o fato de terem um sentido diferente do nosso, sem que o percebamos. Assim, parecendo responde-nos muito precisamente, elas nos falem sem nos entender e sem que as entendamos. Geralmente, deve-se a semelhantes equívocos a surpresa que as vezes suas palavras nos causam, já que lhes atribuímos ideias que as crianças não associam às mesmas palavras (ROUSSEAU, 2004, p. 67).

Finalizando o Livro I de Emílio, Rousseau afirma que os primeiros desenvolvimentos das crianças acontecem quase ao mesmo tempo, andar, falar, comer. Ele considera essa fase, a primeira da vida do indivíduo, sendo muito importante para sua formação. Nesse período do desenvolvimento da criança, o filósofo nos adverte que é importante aprender a sofrer e que essa aprendizagem está relacionada com a felicidade. Nosso autor questiona o que fazer para tornar o homem feliz. Afirma que a felicidade está no equilíbrio entre os desejos e as forças para realizá-los. A educação da criança seria a forma de encontrar esse equilíbrio. Além disso, a criança submetida a esse processo de formação faria por si mesma e não necessitaria 
recorrer a outras pessoas com frequência, desenvolveria, junto com suas forças, o conhecimento.

\section{Considerações finais}

O horizonte que pretendíamos apresentar neste artigo foi justamente buscar refletir a contribuição de Rousseau para o pensamento pedagógico contemporâneo com base em suas obras, muito mais no sentido de compreender suas máximas e princípios fundamentais do que realizar uma transposição direta para compreender a educação da infância na atualidade. Seu sistema filosófico nos ajuda a compreender a constituição dos sujeitos a começar pelos processos formativos destinados à infância em relação a um projeto de sociedade.

A perspectiva de pensar a educação de crianças pequenas em contextos institucionais específicos exige que se retome as diferentes concepções de sociedade, educação e infância que constituíram as bases do pensamento pedagógico e que originaram as formas de atendimento da criança em nosso século.

Para compreender as diferentes dimensões da constituição das propostas que orientam, na atualidade, a educação infantil e a complexidade deste campo é necessário conhecer as bases teóricas e filosóficas que deram origem às muitas propostas educativas existentes. Ao mesmo tempo, devemos compreender a educação infantil como um espaço que contempla a formação de todas as dimensões do ser humano na sua relação com determinado projeto de sociedade.

\section{Referências}

CERIZARA, A. B. Rousseau: a educação na infância. São Paulo: Scipione, 1990.

GUIMARÃES, G. A Recusa da sociedade do espetáculo no processo de formação do homem autônomo: um estudo da abordagem de Rousseau. Belo Horizonte. Tese (Doutorado em Educação) - Faculdade de Educação, Universidade Federal de Minas Gerais, 2004.

ROUSSEAU, Jean-Jacques. Discurso sobre a origem e os fundamentos da desigualdade entre os homens. Trad. de Maria Ermantina Galvão. São Paulo: Martins Fontes, 1999.

. Do contrato social. Trad. Pietro Nassetti. $3^{a}$ Edição. São Paulo: Martin Claret, 2000.

Emílio, ou, Da educação. Trad. Roberto Leal Ferreira - $3^{\text {a }}$ edição. São Paulo: Martins Fontes, 2004. 